\title{
O IMPACTO DO MARKETING INTERNO NA COMPATIBILIDADE DE OBJETIVOS INTERDEPARTAMENTAIS E NA SATISFAÇÃO DO CLIENTE NUMA AGÊNCIA DE PUBLICIDADE
}

\author{
THE IMPACT OF INTERNAL MARKETING ON THE COMPATIBILITY OF \\ INTERDEPARTAMENTAL GOALS AND CUSTOMER SATISFACTION IN AN \\ ADVERTISING AGENCY \\ EL IMPACTO DEL MARKETING INTERNO EN LA COMPATIBILIDAD DE \\ LOS OBJETIVOS INTERDEPARTAMENTALES Y LA SATISFACCIÓN DEL \\ CLIENTE EN UNA AGENCIA PUBLICITARIA
}

\author{
Albérico Rosário (alberico.rosario@esg.ipsantarem.pt) * \\ Rui Cruz (rui.cruz@universidadeeuropeia.pt)** \\ Beatriz Elias (beatriz.elias@hotmail.com)***
}

\section{RESUMO}

O marketing interno representa um papel fundamental no desenvolvimento de uma empresa centrada no cliente, ao motivar e direcionar os colaboradores com o propósito de atingirem, em conjunto, os objetivos organizacionais. Empresas de prestação de serviços têm vindo a demonstrar uma preocupação na melhoria da comunicação interna, com o objetivo de reduzir o isolamento interdepartamental, incentivando assim a cooperação interpessoal e atingir uma maior satisfação do cliente. O presente estudo tem como principal objetivo analisar a relação entre práticas de marketing interno, a compatibilidade de objetivos e o grau de perceção dos colaboradores relativamente à satisfação do cliente no setor da publicidade em Portugal. Através de duas amostras - colaboradores do departamento de contacto e colaboradores do departamento criativo - foi possível uma análise comparativa mais direcionada, possibilitando a demonstração das diferenças existentes nos dois departamentos, com o intuito de perceber quais as dimensões que devem ser mantidas, melhoradas ou, por fim, abandonadas. Os resultados obtidos demonstram que o marketing interno apresenta impacto positivo na compatibilidade de objetivos, assim como na satisfação do cliente, sendo também que compatibilidade de objetivos tem impacto positivo na satisfação do cliente. Já a nível do departamento criativo verificam-se algumas diferenças, pois a relação entre o marketing interno e a satisfação do cliente foi suportada.

Palavras Chave: marketing interno, compatibilidade de objetivos interdepartamentais, satisfação do cliente, setor da publicidade.

\section{ABSTRACT}

Internal marketing plays a fundamental role in the development of a customer-centered company by motivating and directing employees with the aim of jointly achieving organizational goals. Service 


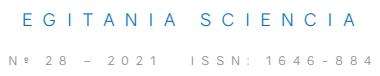

providers have been showing a concern for improving internal communication with the aim of reducing interdepartmental isolation, thus encouraging interpersonal cooperation and achieving greater customer satisfaction. The main objective of this study is to analyze the relationship between internal marketing practices, the compatibility of objectives and the degree of perception of employees regarding customer satisfaction in the advertising sector in Portugal. Through two samples: collaborators from the contact department and collaborators from the creative department, a more targeted comparative analysis was possible, enabling the demonstration of the differences existing in the two departments in order to understand which dimensions should be maintained, improved or, finally, abandoned. The results demonstrate that internal marketing has a positive impact on the compatibility of objectives as well as on customer satisfaction, and also that compatibility of objectives has a positive impact on customer satisfaction. At the creative department level there are some differences as the relationship between internal marketing and customer satisfaction was supported.

Keywords: internal marketing, compatibility of interdepartmental objectives, customer satisfaction, advertising sector.

\section{RESUMEN}

El marketing interno juega un papel fundamental en el desarrollo de una empresa centrada en el cliente al motivar y dirigir a los empleados con el objetivo de lograr conjuntamente los objetivos de la organización. Los proveedores de servicios han mostrado preocupación por mejorar la comunicación interna con el objetivo de reducir el aislamiento interdepartamental, alentando así la cooperación interpersonal y logrando una mayor satisfacción del cliente. El objetivo principal de este estudio es analizar la relación entre las prácticas de marketing interno, la compatibilidad de objetivos y el grado de percepción de los empleados con respecto a la satisfacción del cliente en el sector publicitario en Portugal. A través de dos muestras - colaboradores del departamento de contacto y colaboradores del departamento creativo - fue posible un análisis comparativo más específico, que permitió la demostración de las diferencias existentes en los dos departamentos para comprender qué dimensiones se deben mantener, mejorar o, finalmente, abandonados. Los resultados obtenidos demuestran que el marketing interno tiene un impacto positivo en la compatibilidad de objetivos así como en la satisfacción del cliente, y también que la compatibilidad de objetivos tiene un impacto positivo en la satisfacción del cliente. A nivel del departamento creativo, existen algunas diferencias, ya que se solo apoyó la relación entre el marketing interno y la satisfacción del cliente.

Palabras clave: marketing interno, compatibilidad de objetivos interdepartamentales, satisfacción del cliente, sector publicitario.

* Ph.D. Marketing and Strategy of the Universities of Aveiro (UA), Minho (UM) and Beira Interior (UBI). With affiliation to the GOVCOPP research center of the University of Aveiro. Master in Marketing and Degree in Marketing, Advertising and Public Relations, degree from ISLA Campus Lisbon - European University | Laureate International Universities. Has the title of Marketing Specialist and teaches with the category Assistant Professor at the School of Management and Technology of Santarém (ESGTS) Polytechnic Institute of Santarém, and Assistant Professor IPAM - School of Marketing. He taught at ISLA - Instituto Superior de Gestão e Administracao de Santarém (ISLA-Santarém), was Director of the Commercial Management Course, Director of the Professional Technical Course (TeSP) of Sales and Commercial Management, Chairman of the Pedagogical Council and Member of the Technical Council. ISLA-Santarém Scientific Researcher. He is also a marketing and strategy consultant for SMEs. Her main research interests are: 
Competitive Strategy, Competitive Dynamics, Strategic Groups and Marketing.

**A Assistant Professor at Universidade Europeia in Lisbon since 2001 and ISEC Lisbon since 2019. PhD in Management and Marketing from the University of Sevilla, Spain, also has a DEA from the same university and an MBA in Strategic Foresight at IESFF, Lisbon. Integrated researcherof UNIDCOM research center of the IADE-Universidade Europeia with over 20 years teaching experience at the service of several higher education institutions in the public and private sector, actually teaches academic master's and global graduate programs taught in English in the areas of marketing, logistics and supply chain. Also teaches subjects related with marketing and digital marketing in several of the Executive Masters and post-graduation programs. Advisor and Tutor in master's dissertations in the areas of marketing, digital marketing and entrepreneurship his research interests are in the areas of business strategy, strategic marketing, industrial and services marketing and relationship marketing and has scientific articles published national and internationally and books published in Portugal, Spain, Angola and Brazil. Professionally, he worked in the field of advertising at the service of large international agencies such as Publicis, ITT marketing services and BBDO in Portugal and abroad, throughout the 80 's. Was also marketing director of one of the largest Portuguese banking groups in the 90's and business consultant in the areas of strategy and innovation in the first decade of the 21st century.

***Master Marketing management, IPAM Lisboa.

Submitted: $26^{\text {th }}$ February 2020

Accepted: $1^{\text {st }}$ November 2020 


\section{INTRODUÇÃO}

O principal objetivo do marketing interno é fazer com que todos os colaboradores de uma empresa sintam que são valorizados, com o objetivo de obter trabalho qualificado e, como resultado, reduzir a taxa de rotatividade e aumentar a dedicação no desempenho das tarefas (Berry \& Parasuraman, 1992; Hales \& Mecrate-Butcher, 1994). A satisfação dos colaboradores é fundamental no setor da prestação de serviços (Morgan, 2004).

Práticas de marketing interno são vistas como o instrumento de gestão mais adequado à gestão de pessoas, sendo que estas envolvem a satisfação das necessidades dos colaboradores. Os desafios que as organizações enfrentam atualmente (globalização e mudança tecnológica acelerada), levaram a que estas sentissem necessidade de transformar os seus modelos de gestão, sendo forçadas a procurar novas formas de manter e adquirir uma vantagem competitiva. Os colaboradores com um nível elevado de competências levam a uma maior criação de valor através do papel crucial que representam para a empresa, sendo que estas competências são cada vez mais vistas como um recurso essencial (Kwon, 2009). Posto isto, o potencial humano passa a ser considerado um dos principais recursos da organização, sendo que os colaboradores são considerados fundamentais no sucesso de uma organização.

A presente investigação propõe que o marketing interno pode desempenhar um papel fundamental no aumento das trocas colaborativas entre departamentos, sendo que é também argumentado de que a capacidade de uma empresa alinhar e obter compatibilidade em termos de metas de satisfação do cliente entre departamentos é um canal através do qual o marketing interno pode levar à satisfação do cliente.

Numa pesquisa bibliográfica na B-On a publicações analisadas por pares nos últimos 10 anos, revela a existência de apenas 1.059 artigos, o que aponta para uma relativa aridez neste campo e se a relevância do Marketing Interno já não é tão grande, ao introduzirem-se termos relacionados ao sector dos Serviços o número desce para 673. É esta mesma lacuna que justifica o estudo e a reflexão sobre um setor que movimenta muitos milhões de euros e que é responsável pelo desenvolvimento, lançamento e criação de Marcas.

A investigação do marketing interno no âmbito das agências de publicidade é pois ainda escassa, pelo que seria importante a realização de mais estudos nesta área, com o intuito de potenciar o desenvolvimento de estratégias e identificar possíveis falhas ou oportunidades de desenvolvimento neste setor.

\section{MARKETING INTERNO}

O marketing interno olha para os funcionários como clientes internos, considerando o trabalho como produtos internos que satisfazem as suas necessidades e desejos ao mesmo tempo que cumprem os objetivos da empresa (Berry, 1981). É o método no qual os colaboradores dentro da organização são tratados como clientes internos com base num conjunto de procedimentos e etapas implementadas pela gerência, como recrutamento, formação, desenvolvimento, incentivos, motivação e criatividade, todos os requisitos necessários para que se alcancem os objetivos de todas as partes que lidam com a empresa através de um trabalho eficiente (Aryee et al., 2016).

O principal objetivo do marketing interno é fazer com que todos os colaboradores da empresa se sintam valorizados com o propósito de obter trabalho qualificado e, como resultado, a 
redução da rotatividade dos colaboradores, ausência ao trabalho e, por fim, impulsione a dedicação (Berry \& Parasuraman, 1992; Hales \& Mecrate-Butcher, 1994). As empresas devem respeitar as necessidades e desejos dos colaboradores e considerá-los como os aliados mais confiáveis. É de extrema importância as empresas avaliarem com frequências as necessidades dos seus colaboradores, para que não se note negativamente no desempenho dos mesmos. Um desempenho negativo requer enfrentar consequências negativas, uma das quais perder os melhores colaboradores e, como consequência, os clientes mais fiéis (Berry \& Parasuraman, 1992). Negligenciar o marketing interno acaba por levar à negligência do marketing externo (Gronroos, 1995). A prática de marketing interno dentro de uma empresa contribui, assim, para a dedicação e lealdade dos funcionários de forma positiva (Gronroos, 2000).

Do ponto de vista estratégico, o marketing interno visa tratar os colaboradores como clientes internos, agrupando um conjunto de atividades com o intuito de motivar os mesmos a tornarem-se orientados para o cliente, com o propósito de melhorar o desempenho da empresa (Lings, 2004; Lings \& Greenley, 2010).

Do ponto de vista funcional, o marketing interno baseia-se em atividades organizacionais onde são aplicadas práticas de marketing e de recursos humanos para atingir os diversos objetivos organizacionais (Boukis \& Gounaris, 2014). Aqui, o marketing interno é visto como um conjunto de atividades funcionais que fornecem aos gerentes uma ferramenta para adaptar 0 comportamento dos colaboradores em termos de resultados comportamentais desejados (Lings \& Greenley, 2005). Partindo desta argumentação, as empresas devem-se focar em idealizar funções que envolvam os colaboradores ao máximo, de forma a melhorar o seu desempenho (Lings, 2004).

\subsection{Práticas de marketing interno}

Podemos definir marketing interno como uma atividade organizacional que aplica práticas de marketing para responder às necessidades e expectativas dos colaboradores (Lings, 2004), com o objetivo de transformar a satisfação dos colaboradores e a qualidade do trabalho em satisfação do cliente externo (Frost \& Kumar, 2000). Neste sentido, são identificadas três práticas que definem marketing interno: pesquisa do mercado interno (Piercy, 1995); comunicação interna (Reynoso \& Moores, 1996); e formação dos colaboradores (Tansuhaj, et al., 1988).

Compreender e abordar as necessidades e expectativas dos colaboradores são prioridades para uma empresa que implemente práticas de marketing interno tornando-se, por isso, de extrema importância a pesquisa interna de mercado. Através desta pesquisa, a empresa consegue identificar os segmentos-chave de colaboradores, as suas necessidades e as suas caraterísticas específicas, de forma a implementar estratégias direcionadas para cada segmento (Kohli \& Jaworski, 1990). A comunicação clara dos objetivos e estratégias da empresa a todos os colaboradores ajuda a promover o entendimento compartilhado entre os mesmos. Este processo acaba por estar interligado com as necessidades dos colaboradores, uma vez que são criadas estratégias de comunicação internas apropriadas e que estão ligadas diretamente à satisfação do cliente (Lings, 2004). Esta comunicação serve, portanto, o intuito de aumentar a consciência sobre as interdependências entre todos os colaboradores como um pré-requisito para aumentar a produtividade e a qualidade do serviço prestado aos clientes externos (Boukis \& Gounaris, 2014). Para além disso, a formação dos colaboradores é essencial nas práticas de marketing interno (Gronroos, 1983), uma vez que permite direcioná- 
los para uma melhoria das suas habilidades, conhecimentos e know-how, de forma a garantirem um melhor desempenho (Lings \& Greenley, 2010).

Em suma, práticas de marketing interno focadas na aptidão da empresa em realizar pesquisas sobre as necessidades dos colaboradores, comunicar os objetivos estratégicos e formar colaboradores com o intuito de melhorar o seu desempenho, pode gerar uma maior colaboração entre os vários departamentos (Lings \& Greenley, 2010), o que leva a uma maior satisfação do cliente.

Para além disto, práticas de marketing interno motivam os colaboradores a retribuírem com atitudes e comportamentos positivos (Yang, 2010). Demonstrar comportamentos orientados para o cliente com os clientes de uma empresa é uma forma de retribuir, uma vez que eles ajudam a sustentar um desempenho de vendas mais alto (Park \& Holloway, 2003). Este comportamento é demonstrado quando os colaboradores põem em prática os seus conhecimentos de marketing para ajudar o cliente a tomar uma decisão e a satisfazer as suas necessidades (Stock \& Hoyer, 2002) e é uma tendência dos colaboradores para responder continuamente às necessidades do cliente em ambientes relacionados com o trabalho (Brown, et al., 2002), afetando diretamente os resultados da empresa na ótica do cliente (Bansal et al., 2001).

\subsubsection{As fases do marketing interno}

Não existe uma definição estabelecida dos investigadores sobre "o que é exatamente o marketing interno, o que é suposto fazer, como deve ser feito e quem o deve fazer" (Rafiq \& Ahmed, 2000), no entanto, o crescimento do marketing interno foi identificado como sendo composto por três vertentes: (i) Motivação e satisfação dos colaboradores, (ii) Orientação para o cliente e (iii) Ampliação do conceito de marketing interno (Rafiq \& Ahmed, (1993, 2000); Ahmed \& Rafiq, 1995).

No Tabela 1 são identificadas as vertentes do crescimento do marketing interno, bem como o fundamento teórico apresentado para cada uma dessas vertentes.

Tabela 1 - As vertentes do crescimento do marketing interno.

\begin{tabular}{|c|c|c|}
\hline Vertentes & Conceito & Investigadores \\
\hline \multirow[b]{2}{*}{$\begin{array}{l}\text { Motivação e } \\
\text { satisfação dos } \\
\text { colaboradores }\end{array}$} & $\begin{array}{l}\text { Baseia-se na perceção de que, para ter clientes satisfeitos, é } \\
\text { fundamental ter colaboradores satisfeitos. }\end{array}$ & \multirow[b]{2}{*}{ George (1977) } \\
\hline & $\begin{array}{l}\text { Para atingir esta meta, a empresa deverá olhar para os colaboradores } \\
\text { como clientes internos. Se todos se esforçarem para oferecer melhores } \\
\text { serviços aos clientes internos, os clientes externos receberão um } \\
\text { serviço de maior qualidade. }\end{array}$ & \\
\hline $\begin{array}{l}\text { Orientação para o } \\
\text { cliente }\end{array}$ & $\begin{array}{l}\text { Parte do pressuposto de que, se uma empresa adotar práticas de } \\
\text { marketing interno, os seus colaboradores podem ser influenciados mais } \\
\text { facilmente e, por isso, tornarem-se mais motivados para entender as } \\
\text { necessidades dos clientes, a orientação para o mercado e a } \\
\text { mentalidade com foco nas vendas. }\end{array}$ & Gronroos (1995) \\
\hline $\begin{array}{l}\text { Ampliação do } \\
\text { conceito de } \\
\text { marketing interno }\end{array}$ & $\begin{array}{l}\text { Implica reconhecer o marketing interno como uma ajuda na } \\
\text { implementação da estratégia da empresa. É apresentado como um } \\
\text { mecanismo para reduzir o isolamento departamental e os atritos } \\
\text { interdepartamentais, bem como superar a resistência à mudança. }\end{array}$ & $\begin{array}{l}\text { Rafiq \& Ahmed, } \\
\text { (1993, 2000); } \\
\text { Ahmed \& Rafiq, } \\
\text { (1995) }\end{array}$ \\
\hline
\end{tabular}

\subsubsection{As abordagens de marketing interno}

O conceito de marketing interno foi destacado como um dos pilares críticos de sucesso de qualquer empresa de prestação de serviços (Yildiz \& Kara, 2017). A adoção desse conceito desempenha um papel essencial no desenvolvimento dos relacionamentos entre empresas e 
colaboradores (AL-Ghaswyneh, 2018). Vários estudos sugerem o marketing interno como a prática mais indicada para manter os colaboradores qualificados e experientes, fazendo com que se sintam valorizados, o que, por sua vez, aumenta o moral, melhora o desempenho, a produtividade e, posteriormente, a qualidade do serviço (Berry, 1981; Berry \& Parasuraman, 1992; Boomer, 2004; Grönroos, 1994; Grönroos, 2000; Hales \& Mecrate-Butcher, 1994; Li \& Sheldon, 2010).

Ao analisarmos os diferentes conceitos (Tabela 2), podemos concluir que existem três abordagens mais populares entre os investigadores: (i) O marketing interno é uma estratégia, focada em satisfazer as necessidades dos colaboradores (Berry, 1981); (ii) o marketing interno é uma forma de integrar as diferentes funções essenciais para o melhoramento do relacionamento com os clientes externos (Gronroos, 1983) e (iii) representa a união entre as abordagens e afirmando que o marketing interno representa estratégias que afetam cargos e procedimentos com o objetivo de melhorar a eficácia da empresa, através da colaboração interdepartamental (Rafiq \& Ahmed, 2000).

Tabela 2 - Abordagens de Marketing Interno.

\begin{tabular}{|c|c|}
\hline Abordagens de marketing interno & Investigadores \\
\hline Ml*é um programa baseado na comunicação com os colaboradores. & Berry et al. (1976) \\
\hline $\begin{array}{l}\text { MI*é a filosofia de ver os empregos como produtos internos e colaboradores da } \\
\text { empresa como clientes internos. É implementado através de uma pesquisa interna de } \\
\text { mercado para desenvolver empregos que atraiam e mantenham bons profissionais. }\end{array}$ & Sasser \& Arbeir (1976) \\
\hline $\begin{array}{l}\text { Ml*é a estratégia que enfrenta as preocupações dos colaboradores com o objetivo de } \\
\text { melhorar o atendimento ao cliente. }\end{array}$ & William (1977) \\
\hline $\begin{array}{l}\mathrm{Ml}^{*} \text { é uma estratégia de reestruturação da comunicação interna destinada a formar } \\
\text { colaboradores orientados para o cliente. }\end{array}$ & Berry $(1981 ; 1987)$ \\
\hline $\begin{array}{l}\text { MI é a prática de integrar as diferentes funções dentro de uma empresa essenciais para } \\
\text { o fortalecimento da relação com o cliente. }\end{array}$ & Gronroos (1983) \\
\hline $\begin{array}{l}\mathrm{Ml}^{*} \text { é o processo de alinhar, formar e motivar os colaboradores para o alcance das } \\
\text { metas organizacionais. }\end{array}$ & Winter (1985) \\
\hline Ml é implementado através da comunicação com os colaboradores. & Tansuhaj et al. (2011) \\
\hline $\begin{array}{l}\text { Ml*é implementado através da comunicação com os colaboradores e mecanismos de } \\
\text { mudança. }\end{array}$ & Gummesson (1987) \\
\hline $\begin{array}{l}\text { Ml* é uma ferramenta essencial no desenvolvimento dos colaboradores. Baseia-se nos } \\
\text { esforços de recrutamento, formação, motivação, comunicação e manutenção de } \\
\text { colaboradores. }\end{array}$ & Tansuhaj et al., (2011) \\
\hline $\begin{array}{l}\text { MI é um processo de gestão que visa integrar os departamentos de recursos humanos e } \\
\text { marketing com o intuito de melhorar a orientação dos serviços da empresa. }\end{array}$ & George (1990) \\
\hline $\begin{array}{l}\text { Ml* consiste em atrair, desenvolver, motivar e manter colaboradores qualificados } \\
\text { satisfazendo as suas necessidades, é a filosofia de tratar os colaboradores como } \\
\text { clientes e a estratégia de definir cargos respondendo às necessidades humanas. }\end{array}$ & Berry \& Parasuraman (1993) \\
\hline $\begin{array}{l}\mathrm{Ml} \text { *é implementado através da integração de práticas de marketing e das suas funções, } \\
\text { uma vez que os colaboradores se tornam um recurso para a prática do mesmo. }\end{array}$ & Glassman \& McAfee (1992) \\
\hline $\begin{array}{l}\text { Ml* é um esforço planeado para superar a resistência à mudança organizacional, alinhar } \\
\text { e motivar os colaboradores com o objetivo de implementar estratégias corporativas e } \\
\text { funcionais bem-sucedidas. }\end{array}$ & Ahmed \& Rafiq (1993) \\
\hline $\begin{array}{l}\text { Ml*é implementado através da comunicação, desenvolvimento, motivação e } \\
\text { recompensas. }\end{array}$ & Foreman \& Money (1995) \\
\hline $\begin{array}{l}\text { Ml é implementado através da comunicação interna com o objetivo de vender a } \\
\text { importância do serviço ao cliente. }\end{array}$ & Varey (1995) \\
\hline $\begin{array}{l}\mathrm{Ml}^{*} \text { permite eliminar barreiras entre departamentos de forma a melhorar o } \\
\text { desenvolvimento e a implementação dos objetivos da empresa. }\end{array}$ & Piercy (1995) \\
\hline $\begin{array}{l}\mathrm{Ml*} \text { é o processo de criação de condições de mercado dentro da empresa com a } \\
\text { finalidade de atender os desejos e necessidades dos clientes internos. }\end{array}$ & Ballantyne et al. (1995) \\
\hline $\begin{array}{l}\text { Ml*é um processo que combina o know-how e a autonomia dos colaboradores de } \\
\text { forma a garantir que os desejos e necessidades dos mesmos são cumpridos. }\end{array}$ & Ballantyne (1997) \\
\hline $\begin{array}{l}\text { MI* deverá estar integrado com a função de marketing, uma vez que o marketing é da } \\
\text { responsabilidade dos colaboradores que irão influenciar o valor do cliente. }\end{array}$ & Gronroos (1997) \\
\hline
\end{tabular}




\begin{tabular}{|c|c|}
\hline $\begin{array}{l}\text { MI* é implementado através de pesquisa de mercado interno com o intuito de vender os } \\
\text { objetivos da empresa internamente. }\end{array}$ & Wasmer \& Brunner (1991) \\
\hline $\begin{array}{l}\text { MI* é a filosofia e o comportamento que permite uma mudança organizacional rápida } \\
\text { como resposta aos macro e microambientes da empresa. }\end{array}$ & Varey \& Lewis (1999) \\
\hline $\begin{array}{l}\text { MI* é um esforço planeado que usa uma abordagem semelhante ao marketing para } \\
\text { motivar os colaboradores, oferecer satisfação ao cliente e obter coordenação interna. }\end{array}$ & Rafiq \& Ahmed (2000) \\
\hline $\begin{array}{l}\text { MI refere-se ao uso planeado de práticas de ações de comunicação com o intuito de } \\
\text { influenciar sistematicamente os conhecimentos, atitudes e comportamentos dos } \\
\text { colaboradores atuais. }\end{array}$ & Stauss \& Hoffman (2000) \\
\hline $\begin{array}{l}\text { MI*cé uma estrutura cultural e um instrumento para alcançar o alinhamento estratégico, } \\
\text { ao mesmo tempo que desenvolve competências de atendimento ao cliente, gerindo as } \\
\text { relações internas através da comunicação interna. }\end{array}$ & Ahmed \& Rafiq (2003) \\
\hline $\begin{array}{l}\text { A implementação de Ml é influenciada pelas características individuais e } \\
\text { organizacionais. }\end{array}$ & Naude et al. (2003) \\
\hline $\begin{array}{l}\text { MI* influencia os procedimentos da empresa, facilitando a sua reformulação utilizando } \\
\text { informações do ambiente externo e interno. }\end{array}$ & Ballantyne (2003) \\
\hline $\begin{array}{l}\text { MI* visa tratar os colaboradores da linha da frente como clientes e melhorar a qualidade } \\
\text { do serviço. }\end{array}$ & Lings (2004) \\
\hline $\begin{array}{l}\text { MI* representa o esforço entre orientação do mercado interno e melhoramento do clima } \\
\text { interno. }\end{array}$ & Lings \& Greenley (2005) \\
\hline $\begin{array}{l}\text { MI* é um resumo de crenças específicas e comportamentos específicos de marketing } \\
\text { que promovem a necessidade de planear e construir relacionamentos estáveis entre } \\
\text { colaboradores e gerência. }\end{array}$ & Gounaris (2006) \\
\hline $\begin{array}{l}\text { MI* abrange todo o desenvolvimento de conhecimento, feedback, esforço e processo } \\
\text { de trocas necessárias para apoiar os clientes internos nas suas tarefas diárias. }\end{array}$ & Keller et al. (2006) \\
\hline MI* coloca os colaboradores em primeiro lugar para alcançar os objetivos da empresa. & Proctor (2010) \\
\hline $\begin{array}{l}\text { MI* é uma filosofia de gestão de recursos humanos que denomina empregos como } \\
\text { produtos. }\end{array}$ & Abzari et al. (2011) \\
\hline $\begin{array}{l}\text { MI* baseia-se em atividades organizacionais onde são aplicadas práticas de marketing } \\
\text { e de recursos humanos para atingir os objetivos organizacionais. }\end{array}$ & Boukis \& Gounaris (2014) \\
\hline $\begin{array}{l}\text { MI* olha para os colaboradores como clientes com base num conjunto de } \\
\text { procedimentos e etapas implementadas pela gerência, como recrutamento, formação, } \\
\text { desenvolvimento, incentivos e motivação com o intuito de alcançar todos os objetivos } \\
\text { da empresa. }\end{array}$ & Aryee et al. (2016) \\
\hline $\begin{array}{l}\mathrm{MI*} \text { designa as atividades desempenhadas pelas equipas internas como produtos } \\
\text { internos que, posteriormente, são adquiridos por clientes externos. }\end{array}$ & Yildiz \& Kara, (2017) \\
\hline $\begin{array}{l}\text { Práticas de MI representam a coordenação interdepartamental, através dos esforços } \\
\text { colaborativos dos colaboradores para atingir a meta organizacional e proporcionar } \\
\text { maior valor e satisfação ao cliente externo. }\end{array}$ & Russo e tal. (2017) \\
\hline $\begin{array}{l}\text { MI* designa equipas internas de uma empresa como clientes internos de um mercado } \\
\text { interno. }\end{array}$ & Abbas \& Riaz, (2018) \\
\hline
\end{tabular}

\subsection{A relação entre marketing interno e compatibilidade de objetivos interdepartamentais}

Num ambiente de negócios competitivos, os esforços de colaboração entre departamentos desempenham um papel importante na construção e sustentação das relações com o cliente (Darmon, 2004). É importante ressaltar que os esforços para construir relacionamentos produtivos e executar tarefas focadas no cliente exigem uma estreita colaboração entre equipa de contacto e membros de outros departamentos dentro da empresa, na medida em que atingir a satisfação do cliente exige trocas colaborativas entre um conjunto diversificado de colaboradores (Enz \& Lambert, 2015; Steward et al., 2010).

A abordagem de toda a empresa para responder às necessidades dos clientes externos através das atividades dos colaboradores internos é identificada como práticas de marketing interno. Um argumento que justifica esta abordagem é que, ao envolver os colaboradores como clientes internos, as empresas podem apresentar os seus colaboradores orientados para o cliente como uma forma de encantar os clientes externos (Lings, 2004; Lings \& Greenley, 2010). 
As empresas são divididas em diversas funções/departamentos, em que cada departamento é responsável por lidar com uma parte específica do ambiente externo (Van der Vegt \& Bunderson, 2005). Esta diferenciação interfuncional e departamental resulta, inevitavelmente, em diferenças de objetivos/metas. No entanto, embora diferentes departamentos possam ter objetivos distintos (em termos de grau de semelhança), eles podem ser simultaneamente compatíveis e, quando isso acontece, é gerado um ambiente interno colaborativo, garantindo uma união de esforços que visa alcançar os objetivos organizacionais (Homburg \& Jensen, 2007), incluindo satisfação do cliente. É imprescindível que as empresas criem um ambiente que incentive os esforços colaborativos entre departamentos, com o objetivo de alcançar a satisfação do cliente (Chen \& Lin, 2013).

O marketing interno tem um papel a desempenhar ao reunir objetivos, educar e motivar colaboradores de diferentes departamentos (Chen \& Lin, 2013), rever os seus papéis dentro da empresa e promover a compreensão de que todos os colaboradores desempenham papéis diferentes em diferentes departamentos, sendo uma mais-valia para atingir o objetivo da empresa (Lee \& Chen, 2005). Ao promover o relacionamento com colaboradores de diferentes áreas, o marketing interno desencadeia uma atmosfera na qual a equipa de contacto é incentivada a trabalhar em conjunto com outros membros da empresa para a realização de um objetivo comum (Hughes et al., 2013).

Podemos assim afirmar que a satisfação do cliente é impulsionada pela compatibilidade de objetivos entre o departamento de contacto e outras unidades funcionais, na medida em que a complexidade da tarefa envolvida no atendimento a clientes externos exige que a equipa de contacto dependa de colegas de outros departamentos/funções com os recursos necessários para responder às necessidades dos clientes (Kennedy et al., 2001).

O marketing interno ajuda a gerar compatibilidade de objetivos entre departamentos e funções, garantindo que os objetivos e esforços de cada função sejam direcionados para uma maior satisfação do cliente (Van der Vegt \& Bunderson, 2005).

\subsection{A relação entre marketing interno e a satisfação do cliente}

O impacto do marketing interno na satisfação do cliente é fortalecido através da compatibilidade de objetivos interdepartamentais, quando a equipa de contacto trabalha em equipa com outros colaboradores da empresa. Quanto mais a equipa de contacto está disposta a envolver-se com colaboradores de outros departamentos, mais provável é que essa compatibilidade de objetivos se torne numa interação bem-sucedida de atividades de marketing interno, o que acaba por resultar em satisfação do cliente externo. O objetivo do marketing interno é alcançar a satisfação da equipa a fim de satisfazer as necessidades dos clientes (Kotler et al., 2009) e, qualquer empresa que seja capaz de fornecer aos seus colaboradores programas de conscientização sobre a sua missão, objetivos e requisitos do cliente será capaz de melhorar os seus serviços (Akroush et al., 2013).

A satisfação dos colaboradores foi destacada como um fator crítico na satisfação do atendimento ao cliente (Awan et al., 2015). Os clientes mostram-se mais satisfeitos e com intenção de regressar às empresas quando os colaboradores estão satisfeitos e não abandonam a empresa com frequência. No entanto, a recente expansão das indústrias de serviço tem vindo a permitir que os clientes tenham mais opções para os seus produtos e serviços (Ferrel \& Hartline, 2014), tornando-os assim mais exigentes (Zeithaml \& Bitner, 2000). Estas exigências muitas vezes acabam por causar stress e depressão aos 
colaboradores da empresa e, consequentemente, estes acabam por deixar os seus empregos ou a demonstrar comportamentos contraproducentes (Schwepker, 2003).

A responsabilidade organizacional às solicitações dos colaboradores, a oferta de oportunidades de formação e comunicação harmoniosa são al guns dos aspetos que permitem um maior conforto e felicidade no dia-a-dia dos colaboradores (Ahmed et al., 2003; Bell, Menguc \& Stefani, 2004). Os colaboradores que se mostram satisfeitos com práticas de marketing interno tendem a nutrir um sentimento de afeição para com a empresa, o que faz com que os comportamentos pouco orientados sejam reduzidos e haja um aumento de comportamentos compatíveis com as estratégias da empresa (Ramaswami, 1996). Por sua vez, é mais provável que os colaboradores se manifestem pelos benefícios da empresa, mesmo que estes não sejam recompensados ou pagos pelos seus esforços extra (Awan et al., 2015).

Outra vertente importante quando se fala em satisfação é o sistema de incentivo, que é parte integrante do conceito de marketing interno. Este sistema inclui formas e meios de elevar a moral dos colaboradores que se destacam profissionalmente com o intuito de aumentar a sua lealdade com a empresa, bem como melhorar a sua aptidão para o auto desenvolvimento, a autoconfiança e a eficiência, de forma a continuar a exercer as suas tarefas com mérito (Rony \& Suki, 2017). Esta vertente também motiva a equipa a competir para obter mais produtividade e, para além disso, é um comportamento crucial das políticas das empresas (Tsai, 2014).

Outra parte integrante é a formação, uma das atividades administrativas que visa aumentar a produtividade dos colaboradores e proporcionar-Ihes um conhecimento profissional especializado que possa apoiá-los no desempenho das tarefas e deveres inerentes às suas posições dentro da empresa (Boukis et al., 2015).

A formação desempenha um papel essencial no melhoramento das habilidades da equipa, colmatando as fraquezas e lacunas. É um processo sistemático que visa mudar o comportamento, o conhecimento e a motivação da equipa com o objetivo de aumentar o grau de sincronização e sinergia entre as características e habilidades dos colaboradores (Ismail \& Sheriff, 2017). O processo de formação difere do sistema de promoção em termos de propósito e conteúdo com base em vários fatores. Este concentra-se em medir as capacidades e realizações da equipa e encurtar o ciclo do trabalho dentro de uma empresa (Ahmed \& Rafiq, 2003). Por outro lado, o sistema de promoção concentra-se em atribuir deveres e funções superiores às funções e deveres inerentes à posição atual de uma equipa dentro da hierarquia administrativa da empresa, aumentando as responsabilidades, deveres e status organizacional dos colaboradores, ao mesmo tempo que eleva o salário dos mesmos (Andrews \& Shimp, 2017).

Práticas de marketing interno permitem que as empresas melhorem a relação entre colaborador-empresa. As perceções dos colaboradores relativamente ao marketing interno de uma empresa podem nutrir a sua paixão por demonstrarem comportamentos compatíveis com o foco da empresa (Bell et al., 2004). Para os colaboradores de contacto com o cliente, o envolvimento em comportamentos direcionados para o mesmo torna-se numa paixão, uma vez que as empresas destacam cada vez mais o fornecimento de serviços superiores aos clientes e a manutenção do relacionamento (Marshall \& Johnston, 2015).

O marketing interno influencia a produtividades dos colaboradores juntamente com a sua lealdade, e os comportamentos produtivos dos colaboradores afetam a satisfação e a lealdade do cliente. Para além disso, a lealdade do cliente é um resultado de um aumento dos comportamentos produtivos dos colaboradores. Posto isto, estes comportamentos devem 
intervir na relação entre o marketing interno e os comportamentos leais do cliente, como continuidade de relacionamento e intenção de compra (Heskett et al., 1994).

\section{METODOLOGIA}

Esta investigação tem como objetivo uma melhor compreensão acerca da relação entre o marketing interno e a compatibilidade de objetivos e qual a influência de ambos na satisfação do cliente.

Os dados recolhidos têm o objetivo de analisar a relação entre o marketing interno e a compatibilidade de objetivos e a influência de ambos na satisfação do cliente externo e interno, bem como verificar a coerência entre a perspetiva dos colaboradores de dois departamentos distintos (Contacto e Criativo) dentro da mesma organização. A pesquisa realizada nesta investigação tem um caráter exploratório e descritivo, sendo a técnica considerada a do inquérito por questionário, com o intuito de avaliar as dimensões em causa.

Seguindo uma macroestrutura, este questionário está dividido em 3 categorias, a saber: a primeira pretende avaliar as diversas dimensões do marketing interno de forma a compreender a perceção dos colaboradores e a eficácia desta área na empresa; na segunda parte pretendese avaliar a compatibilidade de objetivos interdepartamentais com o intuito de perceber de que forma o seu alinhamento tem impacto na implementação de práticas de marketing interno e satisfação; na terceira parte pretende-se avaliar a perceção dos colaboradores relativamente à satisfação do cliente externo; de seguida são recolhidas características/informações acerca dos colaboradores, como o género, anos de experiência e departamento em que trabalha. Para uma análise das variáveis foi utilizada uma escala de Likert com seis graus de concordância, sendo que 1 representa discordo totalmente e 6 concordo totalmente.

A estrutura geral do questionário foi principalmente baseada em Huang e Rundle-Thiele (2015), no entanto, houve a necessidade de adaptar e completar esta estrutura à empresa e amostra em questão, perfazendo um total de 25 questões representadas através de 3 dimensões distintas.

Seguindo a estrutura de Huang e Rundle-Thiele (2015), podemos verificar que os seus estudos compreendem as seguintes sub-dimensões de marketing interno: (i) Marketing Interno (sistema de incentivo; Formação; Comunicação Interna; Sistema de promoção).

Ao analisarmos a estrutura de Hwang e Derjang (2005) e Huang e Rundle-Thiele (2015), concluímos que os seus estudos compreendem: (ii) Marketing Interno (Comunicação Interna; Formação; Pesquisa de marketing interno; Conetividade multifuncional do vendedor); (iii) Satisfação; e (iv) Compatibilidade de objetivos (Tabela 3).

Tabela 3 - Escala de Marketing Interno.

\begin{tabular}{|c|c|c|c|}
\hline Sub-Dimensões & & Variáveis & Investigadores \\
\hline \multirow{4}{*}{ Comunicação Interna } & $\mathrm{Cl} 1$ & $\begin{array}{l}\text { Comunico diretamente com os meus chefes para qualquer } \\
\text { dúvida. }\end{array}$ & \multirow{4}{*}{$\begin{array}{l}\text { AL-Ghaswyneh } \\
\text { (2018); Huang e } \\
\text { Rundle-Thiele } \\
\text { (2015); Hwang e } \\
\text { Derjang (2005) }\end{array}$} \\
\hline & $\mathrm{Cl} 2$ & $\begin{array}{l}\text { A agência segue uma política de portas abertas na } \\
\text { comunicação com todos os seus colaboradores. }\end{array}$ & \\
\hline & $\mathrm{Cl} 3$ & $\begin{array}{l}\text { Recebo as informações necessárias da gerência e dos meus } \\
\text { colegas para realizar as minhas tarefas. }\end{array}$ & \\
\hline & $\mathrm{Cl} 4$ & $\begin{array}{l}\text { A agência conta com técnicas modernas de comunicação } \\
\text { entre funcionários-gerência. }\end{array}$ & \\
\hline
\end{tabular}




\begin{tabular}{|c|c|c|c|}
\hline & $\mathrm{Cl} 5$ & $\begin{array}{l}\text { Os colaboradores podem partilhar os seus pontos de vista } \\
\text { sobre as decisões tomadas. }\end{array}$ & \\
\hline & $\mathrm{Cl} 6$ & $\begin{array}{l}\text { A agência incentiva a comunicação dos seus colaboradores } \\
\text { de forma a melhorar o ambiente de trabalho. }\end{array}$ & \\
\hline & $\mathrm{Cl} 7$ & A agência conta com um bom sistema de comunicação. & \\
\hline \multirow{3}{*}{$\begin{array}{l}\text { Pesquisa de } \\
\text { marketing interno }\end{array}$} & $\begin{array}{l}\text { PMI } \\
1\end{array}$ & $\begin{array}{l}\text { A agência procura regularmente sugestões dos } \\
\text { colaboradores. }\end{array}$ & \multirow{3}{*}{$\begin{array}{l}\text { AL-Ghaswyneh } \\
\text { (2018); Huang e } \\
\text { Rundle-Thiele } \\
\text { (2015); }\end{array}$} \\
\hline & $\begin{array}{l}\text { PMI } \\
2\end{array}$ & $\begin{array}{l}\text { A agência tem em consideração o feedback dos } \\
\text { colaboradores. }\end{array}$ & \\
\hline & $\begin{array}{l}\text { PMl } \\
3\end{array}$ & $\begin{array}{l}\text { A agência recolhe dados sobre reclamações dos } \\
\text { colaboradores. }\end{array}$ & \\
\hline \multirow{4}{*}{ Formação } & F1 & $\begin{array}{l}\text { Os programas de formação da agência são apropriados à } \\
\text { minha profissão. }\end{array}$ & \multirow{4}{*}{$\begin{array}{l}\text { AL-Ghaswyneh } \\
\text { (2018); Huang e } \\
\text { Rundle-Thiele } \\
\text { (2015); Hwang e } \\
\text { Derjang (2005); }\end{array}$} \\
\hline & $\mathrm{F} 2$ & $\begin{array}{l}\text { A agência preocupa-se em formar os colaboradores para } \\
\text { desenvolverem as suas competências. }\end{array}$ & \\
\hline & F 3 & $\begin{array}{l}\text { A agência ensina-me a importância e o porquê das minhas } \\
\text { tarefas. }\end{array}$ & \\
\hline & F 4 & $\begin{array}{l}\text { A agência providenciou-me um programa de orientação no } \\
\text { início. }\end{array}$ & \\
\hline \multirow{5}{*}{$\begin{array}{l}\text { O sistema de } \\
\text { incentivo }\end{array}$} & SI 1 & $\begin{array}{l}\text { A agência reconhece os colaboradores que se distinguem } \\
\text { pela sua performance através de incentivos morais. }\end{array}$ & \multirow{5}{*}{$\begin{array}{l}\text { AL-Ghaswyneh } \\
\text { (2018); Huang e } \\
\text { Rundle-Thiele } \\
\text { (2015); Hwang e } \\
\text { Derjang (2005) }\end{array}$} \\
\hline & SI 2 & $\begin{array}{l}\text { O sistema de incentivos oferecido na agência é apropriado à } \\
\text { minha profissão. }\end{array}$ & \\
\hline & SI 3 & $\begin{array}{l}\text { O sistema de incentivos da agência é caracterizado por } \\
\text { justiça e transparência. }\end{array}$ & \\
\hline & SI 4 & O sistema de recompensa incentiva o trabalho em equipa. & \\
\hline & SI 5 & No geral, estou satisfeito com o sistema de incentivo. & \\
\hline
\end{tabular}

A estrutura da dimensão: (ii) satisfação é demonstrada na Tabela 4 e permite, através das variáveis propostas, compreender o nível de contentamento do colaborador face à empresa e ao trabalho desenvolvido na mesma, seja por si próprio, ou por departamentos distintos.

Tabela 4 - Escala da Satisfação.

\begin{tabular}{|c|c|c|c|}
\hline Dimensão & & Variáveis & Investigator \\
\hline \multirow{3}{*}{ Satisfação } & S1 & $\begin{array}{l}\text { Os nossos clientes estão satisfeitos com o serviço que } \\
\text { recebem. }\end{array}$ & \multirow{3}{*}{$\begin{array}{l}\text { Kadic-Maglajlic, S., } \\
\text { Boso, N. e Micevski, } \\
\text { M. (2017); } \\
\text { Huang e Rundle- } \\
\text { Thiele (2015); }\end{array}$} \\
\hline & S 2 & $\begin{array}{l}\text { Os nossos clientes recebem um serviço muito amigável } \\
\text { da equipa. }\end{array}$ & \\
\hline & S 3 & Eu estaria satisfeito se fosse um dos nossos clientes. & \\
\hline
\end{tabular}

A Tabela 5 refere-se à dimensão (iii) compatibilidade de objetivos, que através das variáveis correspondentes, permite analisar o nível de concordância dos diferentes departamentos que podem ou não estar diretamente alinhados com os objetivos da empresa.

Tabela 5 - Escala da Compatibilidade de Objetivos.

\begin{tabular}{|c|c|c|c|}
\hline Dimensão & & Variáveis & Fonte \\
\hline \multirow{3}{*}{$\begin{array}{l}\text { Compatibilidade de } \\
\text { objetivos }\end{array}$} & CO 1 & $\begin{array}{l}\text { Os objetivos do departamento de contacto estão } \\
\text { alinhados com os objetivos do departamento } \\
\text { criativo. }\end{array}$ & \multirow{3}{*}{$\begin{array}{l}\text { Kadic-Maglajlic, S., } \\
\text { Boso, N. e Micevski, M. } \\
\text { (2017); } \\
\text { Huang e Rundle-Thiele } \\
\text { (2015) }\end{array}$} \\
\hline & $\mathrm{CO} 2$ & $\begin{array}{l}\text { Os objetivos do departamento de contacto estão em } \\
\text { harmonia com os objetivos do departamento criativo. }\end{array}$ & \\
\hline & $\mathrm{CO} 3$ & Os objetivos dos 2 departamentos são compatíveis. & \\
\hline
\end{tabular}

Ao analisar ambas as estruturas, houve a necessidade de adaptar a amostra aplicada pelo autor do presente estudo com o intuito de estabelecer a análise proposta nesta investigação sem pôr em causa a veracidade da mesma através das 3 variáveis propostas (i) Marketing Interno, (ii) Satisfação e (iii) Compatibilidade de objetivos, sendo que a sub-dimensão do 
marketing interno - conectividade multifuncional do vendedor - foi retirada desta dimensão por não se identificar com o presente estudo.

O marketing interno propõe uma melhoria interna através de uma base estruturada e comunicada dos objetivos da empresa, dividindo-se assim, nas seguintes sub-dimensões: (i) Comunicação interna; (ii) Pesquisa de marketing interno; (iii) Formação; e, por último, (iv) Sistema de incentivo.

A investigação tem por base os 93 colaboradores do Publicis Groupe em Portugal, que conta com um total de três agências criativas (Leo-Burnett, Publicis e Emil). Para esta investigação consideramos como público-alvo os colaboradores da linha da frente (de contacto com o cliente) e os colaboradores do departamento criativo/estratégia das três agências criativas em 2019, perfazendo um total de 71 inquiridos pertencentes a dois grupos distintos sobre os quais se irá distribuir o mesmo questionário.

O primeiro grupo é constituído por todos os colaboradores de contacto direto com o cliente: Estagiários do departamento de contacto, Accounts, Executivos de Contas, Diretores de Contas e New Business Directors.

O segundo grupo é composto por todo o departamento criativo e de estratégia que conta com: Designers gráficos, Motion Designers, Diretores de Arte, Copywriters, Arte Finalistas, Diretores de Produção Audiovisual, Diretores de Produção Gráfica e Diretores Criativos e Executivos,

Um dos objetivos da presente investigação é a análise da concordância, considerando-se assim duas amostras distintas com o intuito de verificar a coerência de respostas quanto ao tema central, a implementação do marketing interno na empresa e o impacto do mesmo em dois departamentos distintos. Neste contexto, tornou-se relevante filtrar, como proposto pelo autor da estrutura, as informações acerca dos colaboradores, através da seleção do departamento em que desenvolvem as suas funções, sendo que os tipos de funções foram posteriormente adaptados ao presente estudo.

A recolha de dados decorreu durante o mês de agosto de 2019 e o questionário foi distribuído e recolhido pessoalmente de forma a garantir a totalidade das respostas, obtendo um total de 71 questionários válidos a serem considerados para a análise de dados final. O questionário continha uma breve introdução da presente investigação bem como a sua temática, solicitando respostas espontâneas e sinceras, alertando para o facto de o mesmo ser anónimo não devendo ser identificado em qualquer parte, satisfação do cliente externo e interno numa agência de publicidade.

\subsection{Hipóteses de investigação e modelo conceptual}

Embora diferentes departamentos possam ter objetivos distintos (em termos de grau de semelhança), eles podem ser simultaneamente compatíveis e, quando isso acontece, é gerado um ambiente interno colaborativo, garantindo uma união de esforços que visa alcançar os objetivos organizacionais (Homburg \& Jensen, 2007). No entanto, é imprescindível que as empresas criem um ambiente que incentive os esforços colaborativos entre departamentos (Chen \& Lin, 2013). O marketing interno desempenha um papel essencial quando falamos de diferentes objetivos entre departamentos nas empresas, uma vez que, é através das práticas de marketing interno, que os objetivos da empresa são consolidados e, por fim, os objetivos se tornam compatíveis (Lee \& Chen, 2005). 
H1 | O Marketing interno apresenta uma influência positiva na compatibilidade de objetivos interdepartamentais (Tabela 6).

Um dos objetivos do marketing interno é alcançar a satisfação dos colaboradores com o intuito de satisfazer as necessidades dos clientes (Kotler, Keller \& Lu, 2009). O marketing interno é uma abordagem de toda a empresa que tem como objetivo principal responder às necessidades dos clientes externos através das atividades realizadas no ambiente interno (Lings, 2004; Lings \& Greenley, 2010). A qualidade do serviço interno resulta na satisfação, lealdade e produtividade dos colaboradores, o que impulsiona a satisfação do cliente e a fidelidade (Stock \& Hoyer, 2002).

H2 | O Marketing interno tem impacto positivo na satisfação do cliente externo e interno.

Maiores esforços de colaboração por parte de colaboradores de departamentos diferentes ajudam a atingir uma maior satisfação do cliente externo (Ahmed \& Rafiq, 2013).

Por outro lado, o Marketing Interno questiona a estruturação organizacional tradicional por meio da qual as empresas continuam a desenvolver "silos funcionais" considerando que as empresas compreendem que não podem organizar o trabalho como funções separadas, estruturando as suas operações em redor dos principais processos que são orientados ao ponto de vista do cliente Ahmed \& Rafiq (2003)

H3 | A compatibilidade de objetivos tem impacto positivo na satisfação do cliente externo e interno.

Zeithaml \& Bitner (2000) referem o marketing interno como mecanismo que permite entregar as promessas feitas pelo marketing externo. Os funcionários devem ter as habilidades, habilidades, ferramentas e motivação para entregar. As promessas, embora fáceis de fazer, mas podem não ser cumpridas se os funcionários não forem.

Por seu lado Gronroos (p. 14) acrescenta: "Sem esforços ativos e contínuos de marketing interno, o impacto do marketing interativo sobre os clientes se deteriorará, a qualidade do serviço será prejudicada e os clientes começarão a desertar, com efeitos negativos sobre a lucratividade".

Reafirma-se assim que o conceito de Marketing Interno é também é um pré-requisito para o sucesso do marketing externo.

A partir dos fundamentos teóricos presentes na revisão da literatura formularam-se as hipóteses apresentadas na Tabela 6, que visam dar suporte ao presente estudo.

Tabela 6 - Hipóteses formuladas e fundamentos teóricos.

\begin{tabular}{|c|c|c|c|}
\hline & Hipóteses & Fundamento teórico & Investigator \\
\hline $\mathrm{H} 1$ & $\begin{array}{l}\text { O marketing interno apresenta } \\
\text { uma influência positiva na } \\
\text { compatibilidade de objetivos } \\
\text { interdepartamentais. }\end{array}$ & $\begin{array}{l}\text { O marketing interno desempenha um papel essencial } \\
\text { quando falamos de diferentes objetivos entre } \\
\text { departamentos nas empresas, uma vez que, é através } \\
\text { das práticas de marketing interno, que os objetivos da } \\
\text { empresa são consolidados e, por fim, os objetivos se } \\
\text { tornam compatíveis. }\end{array}$ & $\begin{array}{l}\text { Lee \& Chen, } \\
\text { (2005). }\end{array}$ \\
\hline $\mathrm{H} 2$ & $\begin{array}{l}\text { O marketing interno tem } \\
\text { impacto positivo na satisfação } \\
\text { do cliente externo e interno. }\end{array}$ & $\begin{array}{l}\text { A qualidade do serviço interno resulta na satisfação, } \\
\text { lealdade e produtividade dos colaboradores, o que } \\
\text { impulsiona a satisfação do cliente e a fidelidade. }\end{array}$ & $\begin{array}{l}\text { Stock \& Hoyer, } \\
(2002) \text {. }\end{array}$ \\
\hline H3 & $\begin{array}{l}\text { A compatibilidade de objetivos } \\
\text { tem impacto positivo na } \\
\text { satisfação do cliente externo e } \\
\text { interno. }\end{array}$ & $\begin{array}{l}\text { Maiores esforços de colaboração por parte de } \\
\text { colaboradores de departamentos diferentes ajudam a } \\
\text { atingir uma maior satisfação do cliente externo. }\end{array}$ & $\begin{array}{l}\text { Ahmed \& Rafiq, } \\
\text { (2013). }\end{array}$ \\
\hline
\end{tabular}


O modelo conceptual representado na figura 1 que reflete as hipóteses apresentadas. Esta investigação propõe testar o modelo de Chang e Chang (2007).

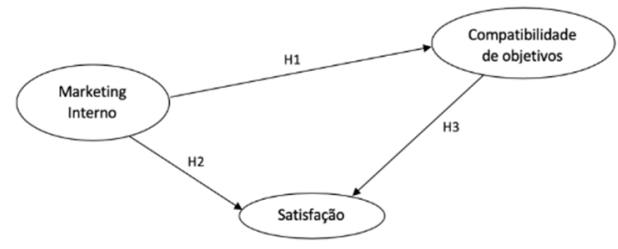

Figura 1 - Modelo Conceptual.

Fonte: adaptado de Chang \& Chang (2007)

\subsection{Método de análise de dados}

A análise e interpretação dos dados obtidos, de forma a testar as hipóteses formuladas a partir da revisão da literatura. Para uma análise e interpretação estatística no programa SPSS versão 25.0.

Através de análises de estatística exploratória e descritiva realizou-se a caracterização da amostra. De seguida, efetuou-se uma análise Univariada de todas as variáveis, dimensões (Marketing Interno, Satisfação e Compatibilidade de Objetivos) e sub-dimensões que integram a dimensão Marketing interno (Comunicação Interna, Pesquisa de Marketing Interno, Formação e Sistema de Incentivo), através de medidas de tendência central e de dispersão, tais como: média, desvio-padrão e variância.

Com o objetivo de avaliar a fiabilidade das escalas das dimensões respetivas, calculou-se o Alfa de Cronbach. Por fim, de forma a testar as hipóteses de investigação, foram realizadas correlações das dimensões e regressões para teste das hipóteses.

\subsection{Caracterização das amostras}

Esta investigação contou com uma amostra de 71 colaboradores do Publicis Groupe em Portugal, o que representa $76 \%$ dos colaboradores totais do grupo e duas amostras: Departamento de Contacto e Departamento Criativo, sendo que obtivemos 39 respostas válidas referentes ao departamento de contacto, representando 54,9\% e 32 respostas válidas no caso do departamento criativo, representando $45,1 \%$.

Relativamente à caracterização estatística da amostra podemos concluir através da Tabela 7 que o género mais representativo no departamento de contacto é o feminino com $40,8 \%$, sendo que, no departamento criativo é o género masculino que predomina com $35,2 \%$.

Quando aos anos de experiência, no departamento de contacto o número de colaboradores com mais de 10 anos de experiência representa $22,5 \%$, a mesma percentagem quando comparado com o número de colaboradores com menos de 5 anos de experiência, sendo que os colabores com 5 a 10 anos de experiência representam apenas 9,9\%. No departamento criativo podemos verificar, tal como no departamento de contacto, a mesma percentagem quando analisamos os colaboradores com menos 5 anos e mais de 10 anos de experiência, 
onde ambos representam $14,1 \%$, destacando-se os colaboradores com 5 a 10 anos de experiência que representam $16,9 \%$, uma percentagem significativa quando comparado com 0 departamento de contacto (Tabela 7).

Tabela 7 - Caracterização da amostra.

\begin{tabular}{lllccc}
\hline \multirow{2}{*}{ Variável } & \multirow{2}{*}{ Categoria } & \multicolumn{4}{c}{ Departamento } \\
\cline { 3 - 6 } & & \multicolumn{2}{c}{ Contacto } & \multicolumn{2}{c}{ Criativo } \\
\cline { 2 - 6 } & $\begin{array}{c}\text { Frequência } \\
\text { Absoluta }\end{array}$ & $\begin{array}{c}\text { Frequência } \\
\text { Relativa }\end{array}$ & $\begin{array}{c}\text { Frequência } \\
\text { Absoluta }\end{array}$ & $\begin{array}{c}\text { Frequência } \\
\text { Relativa }\end{array}$ \\
\hline \multirow{2}{*}{ Género } & Masculino & 10 & $14,1 \%$ & 25 & $35,2 \%$ \\
\hline \multirow{2}{*}{$\begin{array}{l}\text { Anos de } \\
\text { experiência }\end{array}$} & Meminino & 29 & $40,8 \%$ & 7 & $9,9 \%$ \\
\cline { 2 - 6 } & Menos 5 anos & 16 & $22,5 \%$ & 10 & $14,1 \%$ \\
\cline { 2 - 6 } & Mais de 10 anos & 7 & $9,9 \%$ & 12 & $16,9 \%$ \\
\hline
\end{tabular}

\section{RESULTADOS}

O modelo de pesquisa proposto foi testado considerando as duas amostras presentes neste estudo (Departamento de Contacto e Departamento Criativo) através de uma análise comparativa.

A dimensão Marketing Interno é constituída por 19 variáveis que se dividem em quatro subdimensões: (i) Comunicação Interna; (ii) Pesquisa de Marketing Interno; (iii) Formação; e, por último, (iv) Sistema de Incentivo. A avaliar o grau de perceção dos inquiridos relativamente à sub-dimensão Comunicação Interna. Ao analisarmos as variáveis que se destacam nesta subdimensão, verifica-se que a variável $\mathrm{Cl} 1$ "Comunico diretamente com os meus chefes para qualquer dúvida" apresenta a média mais alta $(M=5,42)$ e também valores de desvio-padrão e variância mais baixos $(D P=0,768$; $V A R=0,590)$ demonstrando coerência nas respostas, sendo que a variável $\mathrm{Cl} 4$ "A agência conta com técnicas modernas de comunicação entre colaboradores-gerência" apresenta a média mais baixa $(M=3,27)$ e valores de desvio-padrão e variância altos ( $D P=1,287$; $V A R=1,656)$ representando respostas mais dispersas.

$\mathrm{Na}$ análise desta sub-dimensão (Comunicação Interna) importa também verificar as variáveis que apresentam valores de desvio-padrão e variância maiores, sendo que a Cl2 "A agência segue uma política de portas abertas na comunicação com todos os seus colaboradores" destaca-se pelos valores mais altos ( $M=4,41$; $D P=1,582$; $V A R=2,502)$, assim como a Cl7 "A agência conta com um bom sistema de comunicação" que apresenta valores semelhantes, no entanto, apresenta uma média mais baixa quando comparada à variável $\mathrm{Cl} 2(\mathrm{M}=3,54$; $\mathrm{DP}=1,443$; $\mathrm{VAR}=2,081$ ).

Os valores que dizem respeito à sub-dimensão Pesquisa de Marketing Interno, composta por três variáveis. No geral, nenhum dos resultados adquiridos na análise desta sub-dimensão se destaca, uma vez que as três variáveis apresentam valores muito próximos, no entanto, os resultados diferem em comparação com a sub-dimensão Comunicação Interna, apresentando médias significativamente mais baixas. A variável PMI1 "A agência procura regularmente sugestões dos colaboradores" representa a média mais alta da sub-dimensão $(M=3,18$; $D P=1,334$; $V A R=1,780$ ), seguida pelas variáveis $P M I 2$ "A agência tem em consideração o feedback dos colaboradores" ( $M=2,42$; $D P=1,411$; $V A R=1,990)$ e PMI3 "A agência recolhe dados sobre reclamações dos colaboradores" ( $M=2,37 ; D P=1,427 ; \mathrm{VAR}=2,035)$. Através dos 
valores do desvio padrão e variância podemos ainda verificar que as respostas dos inquiridos a esta sub-dimensão foram consensuais.

Relativamente às quatro variáveis que compõe a sub-dimensão Formação podemos observar, que as médias apresentam valores muito próximos da sub-dimensão Pesquisa de Marketing Interno, no entanto, ao analisarmos o desvio padrão e a variância das variáveis podemos concluir que a sub-dimensão Formação apresenta valores mais altos, representando repostas menos coesas, ou seja, mais diversificadas.

A variável F3 "A agência ensina-me a importância e o porquê das minhas tarefas" representa a média mais alta $(M=3,86 ; D P=1,246 ; V A R=1,551)$, sendo que a variável $F 4$ "A agência providenciou-me um programa de orientação no início" representa a média mais baixa $(M=2,59 ; D P=1,489 ; \operatorname{VAR}=2,216)$.

A última sub-dimensão do Marketing Interno, designada, O Sistema de Incentivo, composta por cinco variáveis que apresentam valores muito semelhantes, no entanto, a variável SI5 "No geral, estou satisfeito com o sistema de incentivo" apresenta a média mais baixa de todas as sub-dimensões que constituem a dimensão Marketing Interno $(M=2,30 ; \quad D P=1,377$; $\operatorname{VAR}=1,897$ ).

Apesar dos valores semelhantes, a variável SI1 "A agência reconhece os colaboradores que se distinguem pela sua performance através de incentivos morais" apresenta a média mais alta $(M=3,00)$ e valores de desvio padrão e variância elevados ( $D P=1,531$; $V A R=2,343)$, representando respostas muito dispersas.

Ao questionar os colaboradores relativamente à perceção da Satisfação do serviço prestado, foi possível constatar que das três variáveis presentes nesta dimensão, a variável S2 "Os nossos clientes recebem um serviço muito amigável da equipa" apresenta a média mais alta $(M=4,59)$, seguida pela variável S1 "Os nossos clientes estão satisfeitos com o serviço que recebem" $(M=3,89)$ e S3 "Eu estaria satisfeito se fosse um dos nossos clientes" $(M=3,87)$.

Analisando o desvio padrão e a variância, podemos concluir que a variável S1 "Os nossos clientes estão satisfeitos com o serviço que recebem" apresenta os valores mais baixos ( $D P=0,854 ; \mathrm{VAR}=0,730$ ), seguida pela variável $S 2$ "Os nossos clientes recebem um serviço muito amigável da equipa" ( $D P=0,904 ; \mathrm{VAR}=0,816$ ) e S3 "Eu estaria satisfeito se fosse um dos nossos clientes" ( $D P=1,362$; VAR=1,855), o que representa uma boa concordância nas respostas adquiridas nesta dimensão.

A dimensão Compatibilidade de Objetivos é composta por três variáveis que permitiram questionar o grau de perceção dos colaboradores relativamente às diferenças interdepartamentais existentes no Publicis Groupe. Podemos concluir que a variável desta dimensão com a média mais alta é a CO3 "Os objetivos dos 2 departamentos são compatíveis" $(M=3,34)$ apresentando também os valores de desvio padrão e variância mais elevados ( $D P=1,241 ; \mathrm{VAR}=1,541$ ), o que representa muita variedade nas respostas dos inquiridos.

A variável CO1 "Os objetivos do departamento de contacto estão alinhados com os objetivos do departamento criativo" apresenta a média mais baixa da dimensão $(M=2,83)$ e através dos valores do desvio padrão e variância ( $D P=1,183$; VAR=1,400) podemos também concluir que os valores representam diversidade das respostas, sendo que a variável $\mathrm{CO} 2$ "Os objetivos do departamento de contacto estão em harmonia com os objetivos do departamento criativo" apresenta valores muito semelhantes $(M=3,07 ; D P=1,163 ; \operatorname{VAR}=1,352)$.

Com o objetivo de testar a fiabilidade do modelo utilizado procedeu-se à análise da consistência interna de cada dimensão (Marketing Interno, Compatibilidade de Objetivos e Satisfação) através da aplicação do coeficiente de consistência interna A/pha de Cronbach. 
O Alpha de Cronbach representa uma medida estatística com valores que variam entre 0 e 1 , devendo apresentar valores superiores a 0,7 para passar o teste de fiabilidade, sendo que a consistência interna é considerada inadmissível para alpha $<0,6$; Fraca para alpha entre 0,6 e 0,7; Razoável para alpha entre 0,7 e 0,8; Boa para alpha entre 0,8 e 0,9; Muito boa para alpha superior a 0,9 (Pestana \& Gageiro, 2008).

$\mathrm{Na}$ dimensão Marketing Interno verifica-se consistência interna muito boa para o departamento de Contacto ( $M=3,38$; $D P=0,887$; e $\alpha=0,930)$ e para o departamento Criativo $(M=3,20 ; \quad D P=1,124 ;$ e $\alpha=0,958)$. A dimensão Compatibilidade de Objetivos deteve consistência interna muito boa ( $M=3,18$; $D P=1,263$; e $\alpha=0,968)$ no departamento de contacto e boa ( $M=2,94 ; \mathrm{DP}=0,950$; e $\alpha=0,891)$ no departamento criativo. Por último, a dimensão Satisfação apresenta consistência interna razoável $(M=4,11 ; D P=0,869$; e $\alpha=0,796)$ no departamento de contacto e boa $(M=4,12$; $D P=0,934$; e $\alpha=0,802)$ no departamento criativo (Tabela 8).

Tabela 8 - Matriz Descritiva das dimensões.

\begin{tabular}{lcccccc}
\hline \multirow{2}{*}{ Dimensões } & \multicolumn{2}{c}{ Média } & \multicolumn{2}{c}{ Desvio Padrão } & \multicolumn{2}{c}{ Alpha Cronbach } \\
\cline { 2 - 7 } & Cont. & Criat. & Cont. & Criat. & Cont. & Criat. \\
\hline Marketing Interno & 3,38 & 3,20 & 0,887 & 1,124 & 0,930 & 0,958 \\
\hline Compatibilidade de objetivos & 3,18 & 2,94 & 1,263 & 0,950 & 0,968 & 0,891 \\
\hline Satisfação & 4,11 & 4,12 & 0,869 & 0,934 & 0,796 & 0,802 \\
\hline
\end{tabular}

De forma a medir o grau de associação linear entre as dimensões Marketing Interno, Compatibilidade de Objetivos e Satisfação em ambas as amostras, foi utilizado o coeficiente de Pearson. O coeficiente de correlação pode variar entre 1 e -1 sendo que um coeficiente menor que 0,2 indica uma associação linear muito baixa; entre 0,2 a 0,39 baixa; 0,4 a 0,69 moderada; 0,7 a 0,89 alta e entre 0,9 e 1 representa uma associação linear muito alta, sendo que, para os valores negativos, deverão ser aplicados os mesmos princípios (Pestana \& Gageiro, 2008).

A Tabela 9 representa a matriz de correlações das duas amostras em análise (Departamento de Contato e Departamento Criativo) e, através da mesma, verifica-se que apesar de todas as dimensões apresentarem correlações positivas, nem todas são estatisticamente significativas, variando entre $r=0,270$ e $r=0,715$, sendo que as correlações do departamento criativo nas dimensões Satisfação e Compatibilidade de Objetivos e Marketing Interno e Compatibilidade de Objetivos não foram consideradas significativas.

A correlação mais elevada é apresentada nas dimensões do departamento de contato Marketing Interno e Satisfação, que apresentam uma correlação positiva e estatisticamente significativa $(r=0,715 ; p<0,01)$, representando uma associação linear alta, o que nos permite afirmar que, com o aumento do Marketing Interno, em média, a Satisfação também aumenta. A correlação positiva mais baixa da matriz é verificada entre as dimensões do departamento de contacto Satisfação e Compatibilidade de Objetivos ( $r=0,611 ; p<0,01)$, representando uma correlação moderada, o que significa que quanto maior for a Satisfação, maior será a Compatibilidade de Objetivos.

A correlação entre as dimensões Satisfação e Marketing Interno do departamento criativo apresenta uma associação linear moderada $(r=0,683 ; p<0,01)$, considerada positiva e estatisticamente significativa ao nível de significância de 1\%. Desta forma, podemos afirmar que existe coerência quando comparado com o departamento de contato uma vez que ambas as dimensões têm tendência a aumentar de modo simultâneo nas duas amostras. 
As dimensões Compatibilidade de Objetivos e Marketing Interno correspondentes à amostra do departamento de contacto apresentam uma correlação alta positiva e estatisticamente significativa $(r=0,712 ; p<0,01)$, comprovando que, quando a Compatibilidade de Objetivos aumenta, o Marketing Interno também apresenta um aumento.

Tabela 9 - Matriz de correlação das dimensões

\begin{tabular}{|c|c|c|c|c|c|c|}
\hline \multirow[t]{2}{*}{ Dimensões } & \multicolumn{2}{|c|}{ Marketing Interno } & \multicolumn{2}{|c|}{$\begin{array}{c}\text { Compatibilidade de } \\
\text { Objetivos }\end{array}$} & \multicolumn{2}{|c|}{ Satisfação } \\
\hline & Cont. & Criat. & Cont. & Criat. & Criat. & Cont. \\
\hline Marketing Interno & 1 & 1 & & & & \\
\hline Compatibilidade de Objetivos & $0,712^{* *}$ & 0,341 & 1 & 1 & & \\
\hline Satisfação & $0,715^{* *}$ & $0,683^{* *}$ & $0,611^{* *}$ & 0,270 & 1 & 1 \\
\hline
\end{tabular}

Notas: ${ }^{* *}$ correlação é significativa no nível 0,01 ( 2 extremidades)

Para uma melhor interpretação do coeficiente de correlação e de forma a medir a percentagem de variabilidade das hipóteses das duas amostras, recorreu-se à análise de regressão linear, que irá verificar a relação funcional das dimensões propostas.

Na Tabela 10 está representada a regressão linear referente à hipótese 1 que tem como variável independente a dimensão Marketing Interno (composta por quatro sub-dimensões Comunicação Interna; Pesquisa de Marketing Interno, Sistema de Incentivo e Formação) e como variável dependente a Compatibilidade de Objetivos. Verifica-se que foi obtido um valor $R^{2}$ ajustado $=0,493$ para o departamento de contacto, o que significa que $49 \%$ da variabilidade total da dimensão Compatibilidade de Objetivos é explicada pelo modelo que tem como dimensão independente o Marketing Interno, ou seja, as práticas de Marketing Interno ajudam a reduzir o erro na estimação da variável Compatibilidade de Objetivos em 49\%.

Relativamente ao departamento criativo observou-se um valor $R^{2}$ ajustado $=0,087$, o que representa que a percentagem de variação total na Compatibilidade de Objetivos explicada pelas práticas de Marketing Interno é de $8 \%$, no entanto, este valor apesar de positivo, não é estatisticamente significativo como comprovado na tabela.

Tabela 10 - Matriz de Regressão Linear - MI-C0.

\begin{tabular}{ccccccccc}
\hline \multirow{2}{*}{ Hipótese } & \multicolumn{2}{c}{$\mathbf{R}$} & \multicolumn{2}{c}{$\mathbf{R}^{2}$} & & \multicolumn{2}{c}{$\mathbf{R}^{2}$ Ajustado } & \multicolumn{2}{c}{$\begin{array}{c}\text { Erro Padrão da } \\
\text { Estimativa }\end{array}$} \\
\cline { 2 - 10 } & Cont. & Criat. & Cont. & Criat. & Cont. & Criat. & Cont. & Criat. \\
\hline $\mathrm{H} 1$ & 0,712 & 0,341 & 0,506 & 0,116 & 0,493 & 0,087 & 0,89929 & 0,90849 \\
\hline
\end{tabular}

Notas: Independente - Marketing Interno; Dependente - Compatibilidade de Objetivos.

De seguida, procedeu-se à regressão linear da hipótese 2 que tem a dimensão Marketing Interno como variável independente e a Satisfação como variável dependente. Como se pode observar através da Tabela 11, o valor de R demonstra que o coeficiente de correlação entre a Satisfação e as práticas de Marketing Interno é de 0,715, sendo que a percentagem de variação total na Satisfação explicada pelas práticas de Marketing Interno $\left(R^{2}\right)$ é de $49 \%$, o que representa uma diminuição do erro na estimação da variável Satisfação em $49 \%$. Posteriormente, ao verificarmos o coeficiente de determinação $\left(R^{2}\right)$ na amostra do departamento criativo verificamos que foi obtido um valor de 0,44 , o que significa que as práticas de Marketing Interno ajudam a reduzir o erro na estimação da variável Satisfação em $44 \%$. 
Tabela 11 - Matriz de Regressão Linear - MI-S.

\begin{tabular}{ccccccccc}
\hline \multirow{2}{*}{ Hipótese } & \multicolumn{2}{c}{$\mathbf{R}$} & \multicolumn{2}{c}{$\mathbf{R}^{\mathbf{2}}$} & \multicolumn{2}{c}{$\mathbf{R}^{\mathbf{2}}$ Ajustado } & \multicolumn{2}{c}{ Erro Padrão da Estimativa } \\
\cline { 2 - 9 } & Cont. & Criat. & Cont. & Criat. & Cont. & Criat. & Cont. & Criat. \\
\hline H2 & 0,715 & 0,683 & 0,512 & 0,467 & 0,499 & 0,449 & 0,61575 & 0,69333 \\
\hline
\end{tabular}

Notas: Independente - Marketing Interno; Dependente - Satisfação.

Na Tabela 12 está representada a regressão linear referente à hipótese 3 que tem como variável independente a Compatibilidade de Objetivos e como variável dependente a Satisfação. No departamento de contacto foi obtido um valor de $R^{2}$ ajustado $=0,374$, o que significa que $37 \%$ da variância total da dimensão Satisfação é explicada pela dimensão Compatibilidade de Objetivos. O departamento criativo apresenta um valor de $R^{2}$ ajustado mais baixo $(0,042)$, sendo que este representa apenas $4 \%$ da variância total da dimensão Satisfação que é explicada pela dimensão Compatibilidade de Objetivos. Este valor apesar de positivo, não é estatisticamente significativo como podemos comprovar na tabela 10.

Tabela 12 - Matriz de Regressão Linear - CO-S

\begin{tabular}{ccccccccc}
\hline \multirow{2}{*}{ Hipótese } & \multicolumn{2}{c}{$\mathbf{R}$} & \multicolumn{2}{c}{$\mathbf{R}^{2}$} & \multicolumn{2}{c}{$\mathbf{R}^{2}$ Ajustado } & \multicolumn{2}{c}{$\begin{array}{c}\text { Erro Padrão da } \\
\text { Estimativa }\end{array}$} \\
\cline { 2 - 10 } & Cont. & Criat. & Cont. & Criat. & Cont. & Criat. & Cont. & Criat. \\
\hline H3 & 0,611 & 0,270 & 0,374 & 0,073 & 0,357 & 0,042 & 0,69746 & 0,91443 \\
\hline
\end{tabular}

Notas: Independente - Compatibilidade de Objetivos; Dependente - Satisfação.

O presente estudo encontrou suporte para as três hipóteses, no entanto, duas hipóteses não foram suportadas na amostra do departamento criativo (Tabela 13).

As práticas de Marketing Interno apresentam uma relação linear positiva e estatisticamente significativa na amostra do departamento de contato $(\beta=1,013 ; p<0,01)$ com a Compatibilidade de Objetivos, sendo que no departamento criativo esta hipótese não apresenta um valor significativo para este estudo $\left(\beta=0,341 ; R^{2} A j u s t a d o=0,087\right)$. Desta forma, a hipótese 1 apenas foi suportada na amostra do departamento de contacto.

A relação linear entre Marketing Interno e a Satisfação foi estatisticamente significativa em ambas as amostras ( $\mathrm{H} 2$ : Contato - $\beta=0,715 ; p<0,01 ;$ Criativo - $\beta=0,683 ; p<0,01$ ), corroborando assim a hipótese 2 .

A Compatibilidade de Objetivos apresenta uma relação linear positiva e estatisticamente significativa no departamento de contacto $(\beta=0,611 ; p<0,01)$ com a Satisfação, sendo que no departamento criativo esta hipótese não apresenta um valor significativo para este estudo $\left(\beta=0,270 ; R^{2}\right.$ Ajustado=0,042). Desta forma, a hipótese 3 apenas foi suportada na amostra do departamento de contacto.

Tabela 13 - Matriz de Regressões.

\begin{tabular}{|c|c|c|c|c|c|c|c|c|}
\hline \multirow{2}{*}{ Hipóteses } & \multirow{2}{*}{$\begin{array}{c}\text { Variável } \\
\text { Independente }\end{array}$} & \multirow{2}{*}{$\begin{array}{c}\text { Variável } \\
\text { Dependente }\end{array}$} & \multicolumn{2}{|c|}{$\beta$} & \multicolumn{2}{|c|}{ Valor $t$} & \multicolumn{2}{|c|}{ Resultado } \\
\hline & & & Cont. & Criat. & Cont. & Criat. & Cont. & Criat. \\
\hline $\mathrm{H} 1$ & Marketing Interno & $\begin{array}{c}\text { Compatibilidade de } \\
\text { Objetivos }\end{array}$ & 1,013 & 0,341 & 6,161 & 1,989 & suportada & $\begin{array}{c}\text { Não } \\
\text { suportada }\end{array}$ \\
\hline $\mathrm{H} 2$ & Marketing interno & Satisfação & 0,715 & 0,683 & 6,229 & 5,127 & Suportada & Suportada \\
\hline $\mathrm{H} 3$ & $\begin{array}{c}\text { Compatibilidade de } \\
\text { Objetivos }\end{array}$ & Satisfação & 0,611 & 0,270 & 4,699 & 1,535 & Suportada & $\begin{array}{c}\text { Não } \\
\text { suportada }\end{array}$ \\
\hline
\end{tabular}




\section{CONCLUSÕES}

O objetivo geral deste trabalho centrou-se em procurar compreender de que forma as práticas de marketing interno impactam na compatibilidade de objetivos e na satisfação do cliente numa empresa de prestação de serviços na área da publicidade em Portugal, em específico, no Publicis Groupe.

Para tal, realizou-se uma análise Univariada que verificou que as médias das três dimensões propostas (Marketing Interno, Compatibilidade de Objetivos e Satisfação do Cliente) demonstraram diferenças significativas relativamente ao grau de perceção dos colaboradores. Apesar da sub-dimensão Comunicação Interna pertencente à dimensão Marketing Interno apresentar uma média elevada, não se verificou coerência quando comparada com as restantes sub-dimensões (Pesquisa de Marketing Interno, Formação e Sistema de Incentivo) que apresentaram médias mais baixas, o que parecer demonstrar que, apesar da empresa contar com uma Comunicação Interna consistente no que diz respeito à comunicação com os colaboradores, relacionamentos internos e bom ambiente de trabalho, a Pesquisa de Marketing Interno, a Formação e o Sistema de Incentivo deverão ser indicativos imprescindíveis e a ter em linha de conta quando são demonstradas práticas de marketing interno.

A análise de Fiabilidade demonstrou, através do Alpha de Cronbach, que as três dimensões presentes neste estudo: Marketing Interno, Compatibilidade de Objetivos e Satisfação apresentaram bons níveis de consistência interna no departamento de contacto e no departamento criativo, variando entre 0,796-0,968.

No que diz respeito às hipóteses formuladas, a hipótese 1 foi suportada parcialmente, uma vez que as práticas de marketing interno apresentam uma influência positiva na compatibilidade de objetivos apenas no departamento de contacto, demonstrando que estas não influenciam o departamento criativo, aspeto que poderá estar relacionado com o maior "afastamento" destes profissionais do contacto diário com os clientes.

A hipótese 2, foi suportada no departamento de contacto e no departamento criativo. Posto isto, pode-se afirmar com base no presente estudo, que práticas de marketing interno aumentam a satisfação do cliente.

Relativamente à hipótese 3 , que sugeria que a compatibilidade de objetivos tem impacto positivo na satisfação do cliente, foi validada parcialmente uma vez que a hipótese encontrou suporte apenas para o departamento de contacto, demonstrando que esta relação não influencia significativamente o departamento criativo, novamente evidenciando que 0 afastamento quotidiano destes colaboradores do contacto com os clientes, e que não é sua função prioritária, poderá ter aqui alguma relação

Os resultados e conclusões obtidos demonstram uma influência significativa do Marketing Interno na satisfação do cliente em ambas as amostras, no entanto, no que diz respeito ao cliente interno, as práticas de marketing interno deverão ser melhor exploradas e aplicadas, sendo que estas poderão ser ferramentas essenciais na estratégia de recursos humanos para atingir a compatibilidade de objetivos interdepartamentais necessários de forma a serem atingidos os objetivos da organização. Uma das limitações do presente estudo, deve-se ao facto do mesmo não apresentar uma amostra maior, sendo que para investigações futuras, seria pertinentes dados mais representativos através do direcionamento para várias agências de publicidade. Com o objetivo de analisar este setor em Portugal e, por consequente 
apresentar soluções mais abrangentes de melhoria, recomenda-se a adição da dimensão desempenho/motivação.

Posteriormente, poderia ser acrescentado valor através da realização de uma abordagem qualitativa, de forma a compreender de que forma os colaboradores olham para as práticas de marketing interno e de que forma as mesmas iriam influenciar a sua relação com a empresa, nomeadamente analisar e aprofundar questões relacionadas ao pessoal criativo e de produção numa óptica de relacionamento com fornecedores, ou do pessoal de media no relacionamento com meios de comunicação ou centrais de compras.

Relativamente às escalas presentes nesta investigação, para investigações futuras, poderia seria pertinente adicionar sub-dimensões à dimensão satisfação e à dimensão compatibilidade de objetivos com o intuito de realizar uma análise mais detalhada das variáveis em questão.

\section{BIBLIOGRAFIA}

Ahmed, P. K. \& Rafiq, M. (1995). Internal marketing issues and challenges. European Journal of Marketing, Vol.37 No9,1177-1186.

Ahmed, P. K. \& Rafiq, M. (1995). The role of internal marketing in the implementation of marketing strategies. Journal of Marketing Practice: Applied Marketing Science, 1(4),32-5.

Ahmed, P. K., \& Rafiq, M. (2003). Internal marketing issues and challenges. European Journal of Marketing, 37(9), 1177-1186.

Akroush, M. N., Abu-ElSamen, A. A., Samawi, G. A., \& Odetallah, A. L. (2013). Internal marketing and service quality in restaurants. Marketing Intelligence \& Planning, 31(4), 304-336.

AL-Ghaswyneh, O. F. M. (2018). Pillars of Internal Marketing and their impact on staff performance. Marketing and Management of Innovations, Issue 2, 313-326.

Anderson, E., \& Sullivan, M. (1993). The Antecedents and Consequences of Customer Satisfaction for Firms. Marketing Science. 12, 125-143.

Andrews, J. C., \& Shimp, T. A. (2017). Advertising, promotion, and other aspects of integrated marketing communications: Nelson Education.

Aryee, S., Walumbwa, F. O., Seidu, E. Y., \& Otaye, L. E. (2016). Developing and leveraging human capital resource to promote service quality: Testing a theory of performance. Journal of management, 42(2), 480-499.

Awan, H. M., Siddiquei, A. N., Jabbar, A., Abrar, M., \& Baig, S. A. (2015). Internal marketing and customer loyalty: A dyadic analysis. Journal of Service Science and Management, 8(2), 1-12.

Awan, H. M., Siddiquei, A. N., Jabbar, A., Abrar, M., \& Baig, S. A. (2015). Internal marketing and customer loyalty: A dyadic analysis. Journal of Service Science and Management, 8(2), 1-12.

Balta, S. (2018). The influence of Internal Marketing on Employee Satisfaction in the Service Industry. Business Management Dynamics, Vol. 8, No. 01, 12-15.

Bansal, H. S., Mendelson, M. B. \& Sharma, B. (2001). The impact of internal marketing activities and external marketing output. Journal of Quality Management. Vol. 6; No.1, 61-76

Bell, S. J., Menguc, B., \& Stefani, S. (2004). When customers disappoint: A model of relational internal marketing and customer complaints. Journal of the Academy of Marketing Science, 32(2), 112-126.

Bell, S. J., Menguc, B., \& Stefani, S. (2004). When customers disappoint: A model of relational internal marketing and customer complaints. Journal of the Academy of Marketing Science, 32(2), 
$112-126$.

Berry L. (1981). The Employee as Customer. Journal of Retail Banking, p. 25-28.- Vol. 3.

Berry, L. (1981). The employee as customer. Journal of Retail Banking, 3, 25-28.

Berry, L. \& Parasuraman, A. (1992). Prescriptions for a Service Quality Revolution in America. Organizational Dynamics, (4), 5-15

Boomer, L. G. (2004). Five Key Decisions to EnhanceYour Human Assets. Accounting Today, 18(6), 20-21.

Boukis, A., \& Gounaris, S. (2014). Linking IMO with employees' fit with their environment and reciprocal behaviours towards the firm. Journal of Services Marketing, 28(1), 10-21.

Boukis, A., Kaminakis, K., Siampos, A., \& Kostopoulos, I. (2015). Linking internal marketing with customer outcomes. Marketing Intelligence \& Planning, 33(3), 394-413.

Brown, T. F., Mowen, J. C., Donavan, D. T., \& Licata, J. W. (2002). The customer orientation of service workers: Personality trait effects on self-and supervisor performance ratings. Journal of Marketing Research, 39(1), 110-119.

Chang. S. \& Chang, H (2007). Effect of internal marketing on nurse job satisfaction and organizational commitment: Example of medical centres in southern Taiwan. Journal of Nursing Research, 15(4), 265-273.

Chen, Y. C., \& Lin, S. (2013). Modeling internal marketing and employee loyalty: A quantitative approach. Asian Social Science, 9(5), 99.

Chen, Y. C., \& Lin, S. (2013). Modelling internal marketing and employee loyalty: A quantitative approach. Asian Social Science, 9(5), 99.

Darmon, R. Y. (2004). Controlling sales force turnover costs through optimal recruiting and training policies. European Journal of Operational Research, 154(1), 291-303.

Enz, M. G., \& Lambert, D. M. (2015). Measuring the financial benefits of cross-functional integration influences management's behaviour. Journal of Business Logistics, 36(1), 25-48.

Ferrell, O. C., \& Hartline, M. D. (2014). Marketing strategy: text and cases (6th ed.). Mason, OH: South-Western/Cengage Learning.

Frost, F. A., \& Kumar, M. (2000). Intservqual-an internal adaptation of the GAP model in a large service organisation. Journal of Services Marketing, 14(5), 358-377.

George, W. R. (1977) The retailing of services a challenging future. Journal of Retailing, Fall, 85-98

Gounaris, S. (2006). Internal market orientation and its measurement. Journal of Business Research, 59(4), 432-448.

Gronroos C. (1985). Internal Marketing Theory and Practice in Services Marketing in a Changing Environment - The American Marketing Association Chicago, p.41-47.

Gronroos, C. (1983). Service marketing: Theory and practice. Cambridge, MA: Marketing Science Institute.

Gronroos, C. (1985). Internal marketing-Theory and practice. Chicago, IL: American Marketing Association, 41-47

Gro" nroos, C. (1995). Relationship marketing: the strategy continuum. Journal of the Academy of Marketing Sciense. 23(4):252 -4

Gro" nroos, C. (2000). Service Management and Marketing. A Customer Relationship Management Approach. Chichester: John Wiley.

Hales, C., \& Mecrate-Butcher, J. (1994). Internal Marketing and Human Resource Management in Hotel Consortia. International Journal of Hospitality Management, 13(4), pp.313-326.

Heskett, J. L., Jones, T. O., Loveman, G. W., Sasser, W. E., Jr., \& Schlesinger, L. A. (1994). Putting the 
service-profit chain to work. Harvard Business Review, 72(2), 164-170.

Homburg, C., \& Jensen, O. (2007). The thought worlds of marketing and sales: Which differences make a difference? Journal of Marketing, 71(3), 124-142.

Huang, Y. T., \& Rundle-Thiele, S. (2015). A holistic management tool for measuring internal marketing activities. Journal of Services Marketing, 29(6/7), 571-584.

Hughes, D. E., Bon, J. L., \& Rapp, A. (2013). Gaining and leveraging customer-based competitive intelligence: The pivotal role of social capital and salesperson adaptive selling skills. Journal of the Academy of Marketing Science, 41(1), 91-110.

Hwang, S., \& Der-Jang, C. (2005). Relationships among internal marketing, employee job satisfaction and international hotel performance: An empirical study. International Journal of Management, 22(2), 285.

Ismail, W., \& Sheriff, N. (2017). The effect of internal marketing on organizational commitment: an empirical study in banking sector in Yemen. Polish Journal of Management Studies, 15.

Jain, S. (2013). The Concept of Employee Branding and Its Effectiveness as a Tool for Employee Retention. Indian Streams Research Journal, 3(3), pp.1-4.

Kadic-Maglajlic, S., Boso, N. \& Micevski, M. (2017). How internal marketing drives costumer satisfaction in matured and maturing European markets. Journal of Business Research 86, 291-299.

Kennedy, M. S., Ferrell, L. K., \& LeClair, D. T. (2001). Consumers' trust of salesperson and manufacturer: An empirical study. Journal of Business Research, 51(1), 73-86.

Kohli, A. K., \& Jaworski, B. J. (1990). Market orientation: The construct, research pro- positions, and managerial implications. Journal of Marketing, 1-18.

Kotler, P., Keller, K. L., \& Lu, T. (2009). Marketing management in China: Prentice Hall.

Kukreja, J. \& Kalkaji, J. (2017). Internal Marketing: a prelude or an outcome of Employee Motivation? BVIMSR's Journal of Management Research, Vol. 9 Issue 1, 54-59.

Lee, C., \& Chen, W. J. (2005). The effects of internal marketing and organisational culture on knowledge management in the information technology industry. International Journal of Management, 22(4), 661-672.

Li, Y. \& Sheldon, P. (2010). HRM Lives Inside and Outside the Firm: Employers, Skill Shortagesand the Local Labour Market in China. The International Journal of Human Resource Management, 21(12), pp.2173-2193.

Lings, I. N. (2004). Internal market orientation: Construct and consequences. Journal of Business Research, 57(4), 405-413.

Lings, I. N., \& Greenley, G. E. (2005). Measuring internal market orientation. Journal of Service Research, 7(3), 290-305.

Lings, I. N., \& Greenley, G. E. (2010). Internal market orientation and market-oriented behaviours. Journal of Service Management, 21(3), 321-343.

Malhotra K. (2011). Pesquisa de Marketing: Uma Orientação Aplicada.- 3a edic, ão- Porto Alegre: Bookman

Marshall, G. W., \& Johnston, M. W. (2015). Marketing management (2nd ed.). New York: McGrawHill Education.

Park, J. \& Tran, T. (2018). Internal Marketing, employee costumer-oriented behaviors, and costumer behavioural responses. Wiley Periodicals 35, 412-426.

Park, J. E., \& Holloway, B. B. (2003). Adaptive selling behaviour revisited: An empirical investigation of learning orientation, sales performance and job satisfaction. Journal of Personal Selling \& Sales Management, 23(3), 239-251.

Pestana, Maria Helena \& Gageiro, João Nunes (2008). Análise de Dados para Ciências Sociais. A 
complementaridade do SPSS, 5ạ edição revista e corrigida. Lisboa, Edições Sílabo, pp. 527-528.

Piercy, N. F. (1995). Customer satisfaction and the internal market: Marketing our customers to our employees. Journal of Marketing Practice: Applied Marketing Science, 1(1), 22-44.

Rafiq, M., Ahmed, P. (1993). The scope of internal marketing: defining the boundary between marketing and human resource management. Journal of Marketing Management, 9, 219-32.

Rafiq, M., Ahmed, P. (2000). Advances in internal marketing: Definition, synthesis and extension. Journal of Services Marketing, 14(6): 449-462.

Ramaswami, S. N. (1996). Marketing controls and dysfunctional employee behaviours: A test of traditional and contingency theory postulates. Journal of Marketing, 60(2), 105-120.

Reynoso, J. F., \& Moores, B. (1996). Internal relationships. Relationship marketing: Theory and practice, 55-73.

Rony, N. I., \& Suki, N. M. (2017). Modelling the Relationships between Internal Marketing Factors and Employee Job Satisfaction in Oil and Gas Industry. Asian Social Science, 13(3), 135.

Schwepker, C. H., Jr. (2003). Customer-oriented selling: A review, extension, and directions for future research. Journal of Personal Selling \& Salesman agreement, 23(2), 151-171.

Steward, M. D., Walker, B. A., Hutt, M. D., \& Kumar, A. (2010). The coordination strategies of highperforming salespeople: Internal working relationships that drive success. Journal of the Academy of Marketing Science, 38(5), 550-566.

Stock, R. M., \& Hoyer, W. D. (2002). Leadership style as driver of salespeople's customer orientation. Journal of Market-Focused Management, 5(4), 355-376.

Tansuhaj, P.; Randall, D. \& McCullough, J. (1988). A services marketing management model: integrating internal and external marketing functions. The Journal of Services Marketing. Vol. 2, No1 winter, 31-38

Tsai, Y. (2014). Learning organizations, internal marketing, and organizational commitment in hospitals. BMC health services research, 14(1), 152.

Van Der Vegt, G. S., \& Bunderson, J. S. (2005). Learning and performance in multi- disciplinary teams: The importance of collective team identification. Academy of Management Journal, 48(3), 532-547.

Varey, R.J. (1995). Internal marketing: a review and some interdisciplinary research challenges. International Journal of Service Industry Management. Vol.6, No1, 40-63

Yang, W. H. (2010). Relationships among internal marketing perceptions, organizational support, job satisfaction and role behaviour in healthcare organizations. International Journal of Management, 27, 235-242.

Yildiz, S. M., \& Kara, A. (2017). A unidimensional instrument for measuring internal marketing concept in the higher education sector: IM-11 scale. Quality Assurance in Education, 25(3).

Zeithaml, V., \& Bitner, M. J. (2000). Services marketing: Integrating customer focus across the firm. New York: McGraw-Hill-Irwin. 
